\title{
The effects of vocational education on adult skills, employment and wages: What can we learn from PIAAC?
}

\author{
Giorgio Brunello ${ }^{1,2,3,4}$ • Lorenzo Rocco'
}

Received: 26 June 2017 / Accepted: 26 September 2017 / Published online: 25 October 2017

(C) The Author(s) 2017. This article is an open access publication

\begin{abstract}
We have shown that vocational education does not perform as well as academic education both in labour market outcomes and in the level of basic skills, including literacy and numeracy. This is especially true for higher education. Only at the upper secondary or post-secondary level does vocational education perform slightly better than academic education in the probability of being currently employed as well as in the time spent in paid employment, although the differences we find are small.
\end{abstract}

Keywords Vocational education - Academic education · PIAAC $\cdot$ Skills · Employment · Wage

JEL Classification I $21 \cdot$ I24 $\cdot 126$

\begin{abstract}
This paper is based on research commissioned by the OECD. The views expressed here are those of the authors and cannot be attributed to the OECD or its member countries. We are grateful to Glenda Quintini, Stijn Broecke, the participants at the Fifth Workshop on "The Economics of Education", University of Barcelona, and at "The International Conference on PIAAC and PIAAC_-Longitudinal", Mannheim, for comments and suggestions. The usual disclaimer applies.
\end{abstract}

\footnotetext{
$凶$ Giorgio Brunello

giorgio.brunello@unipd.it

1 University of Padova, Padova, Italy

2 Cesifo, Munich, Germany

3 IZA, Bonn, Germany

4 ROA, Maastricht, Netherlands
} 


\section{Introduction}

Vocational education and training (VET) are highly valued by many. For instance, VET is expected to play an important role in achieving two Europe 2020 headline targets set in the education field: (a) reduce the rate of early school leavers from education to $<10 \%$; (b) increase the share of 30-40 years old having completed tertiary or equivalent education to at least $40 \%$.

In this paper we investigate the effects of VET on adult skills and labour market outcomes by using the PIAAC survey. Data comparability across countries, the breath of countries involved, and the almost unique presence of information on assessed skills, training, earnings and employment makes this survey especially valuable to study the different facets of VET as compared to more academic education.

Our approach is to consider the education careers available to individuals as alternative treatments in a multivalued treatment framework. Focusing mainly but not exclusively on upper secondary, post-secondary and tertiary education, we assume that individuals are exposed to four alternative treatments: (1) vocational education at the upper secondary or post-secondary level; (2) academic education at the upper secondary or post-secondary level; (3) vocational education at the tertiary level; (4) academic education at the tertiary level.

Our key assumption is that, after controlling for individual differences in parental education, country of birth and the number of books in the house, the assignment of individuals to these treatments can be considered as good as random. This assumption implies that our selection on observables is capable of controlling for the sources of self-selection into educational tracks. We discuss its plausibility in the context of the data being used. This is important for the interpretation of our results.

Only when this assumption holds we can interpret our estimates of the effects of alternative treatments as causal effects. When it does not, a more modest interpretation is in order, that views our findings as interesting correlations at best. In particular, if there are factors affecting selection into different curricula that we cannot control for with the data at hand, our estimates are affected by selection bias, which could amplify the estimate gap in labour market outcomes associated to alternative curricula. For instance, failure to properly control for unobserved ability could increase the estimated premium associated to academic curricula if individuals with higher ability are less likely to select into vocational tracks.

When we compare the labour market payoffs accruing to vocational and academic education at ISCED 3 and 4 (upper secondary and post-secondary education), we find that a vocational curriculum is associated to slightly lower hourly earnings, a higher probability of being currently employed, and a higher share of the completed working life spent in paid employment. The estimated differences are small: for earnings, the negative gap ranges between $-1.3 \%$ for males and $-4.8 \%$ for females; for the probability of employment and the share of time spent in paid employment, the estimated positive gaps are 2.2 and $3.3 \%$ points for males and 1.9 and $0.6 \%$ points for females.

The contrast between vocational and academic education is much sharper when we consider tertiary education (ISCED 5). In this case, the earnings gap between 
vocational and academic education at the time of the interview is as big as $-19 \%$ for males and $-21.7 \%$ for females. There is also a small negative gap in the probability of being currently employed. This gap should however be contrasted with the positive gap in the share of the working life spent in paid jobs, estimated at $6.9 \%$ points in the case of males and at $3.7 \%$ points in the case of females. Overall, the evidence we have on different ISCED levels is that vocational education does not perform as well as academic education when earnings are concerned, and performs slightly better than academic education when employability measures are considered.

Independently of the ISCED level, we find that individuals with vocational education have a higher likelihood of being NET (not employed and with no education or training in the past 12 months), report poorer health and have poorer civic behaviour than comparable individuals with academic education. There is also evidence that vocational education is associated to poorer labour market returns among older than younger cohorts. Whether these differences simply reflect cohort effects or also indicate the presence of age effects is impossible to tell with the data at hand, which are a cross section of individuals. This is an important issue that must be left to better data and further research.

When we consider the proficiency in foundation skills we find that those with a vocational education tend to be less effective than those with an academic education, for any ISCED level. This is true for both genders and, in spite of some heterogeneity, for all countries. The negative gap is larger for those with tertiary education and increases with the country-specific share of vocational students. In particular, we estimate that the negative percentage gap associated to vocational education at the secondary or post-secondary level ranges from -2.0 to $-2.2 \%$ for literacy, from -1.9 to $-2.9 \%$ for numeracy and from -1.8 to $-2.3 \%$ for problem solving skills. In the case of tertiary education, the negative gap is larger and ranges from -5.7 to $-5.9 \%$ for literacy, from -6.7 to $-7 \%$ for numeracy and from -4.4 to $-4.7 \%$ for problem solving skills.

There is evidence that the wage and employment returns to VET are higher in countries where the relative supply of VET graduates is lower. In these countries, skill performance by VET graduates is also better. However, in spite of the growing interest attracted by dual systems, which alternate school and work, we do not find systematic evidence that returns to VET are higher in the countries where vocational education systematically combine school and work.

The paper is organised as follows. Section 2 provides a review of the literature. Our empirical approach is discussed in Sect. 3. The data are briefly introduced in Sect. 4. Results for skills and competencies are presented in Sect. 5, and results for employment and earnings are discussed in Sect. 6. Conclusions follow.

\section{Review of the empirical literature}

Vocational education and training (VET) is frequently perceived as improving the opportunities of youths who lack the resources, skills or motivation to continue with higher education. Many have argued that VET provides useful skills to prepare these individuals for labour market entry and improve their chances of a successful pro- 
fessional career. In an influential paper, Ryan (2001), summarises the cross-country evidence, indicating that vocational programmes, and in particular apprenticeships, increase the chances of an early working life.

While there are virtually no studies investigating the effects of VET on skills, substantial research has been devoted in the past few decades to explore how VET affects labour market outcomes, including earnings and current employment status. This research has produced estimates of the economic returns to different curricula, focusing in particular on the comparison between academic education and VET. Data limitations have generally restricted cross-country comparative analysis, limiting the focus to national case studies.

U.S. based research includes Hotchkiss (1993), who studies the effects of vocational schooling on employment and wages for high-school graduates in 1980, finding no returns to vocational schooling even after controlling for training-related occupation choice. In contrast, Bishop and Mane (2004), find that students who take a certain percentage of vocational subjects in secondary school are more likely to earn higher wages and display higher participation rates compared with academic education students. Meer (2007), also find positive wage effects, but smaller than in Bishop and Mane.

In the UK, Dearden et al. (2002), find that academic education leads to higher returns, but also document that the majority of vocational education programs increase earnings relative to no vocational qualification, especially for low achieving school leavers. One exception is the NVQ2, a VET course often undertaken during employment, which seems to have a negative impact on the wages of individuals, even relative to those with no other qualification (Dearden et al. 2004). More recently, Bibby et al. (2014), compare returns to different curricula using matched administrative data and find that returns to workplace level VET are higher than those from classroom level VET.

Empirical research on the economic effects of VET is plagued by the difficult task of controlling for endogenous selection into different curricula in a credible way. ${ }^{1}$ The few studies which have been able to use exogenous policy changes affecting the duration of academic education in vocational tracks tend to find no statistically significant effects of vocational education on wages or employment probabilities.

Oosterbeek and Webbink (2007), evaluate the effect of extending 3-years basic vocational programs with 1 year of academic education-a policy that took place in the Netherlands in 1975-on later wages. Adopting a difference-in-differences strategy, they investigate the effect of the change on wages 20 years later, but do not find any effect. Pischke and von Wachter (2008), exploit the gradual adoption of a 1 year increase in compulsory schooling in the lowest schooling track in Germany between the 1950 to the 1970 s, investigating the changes on long-term wages, but also fail to find an effect. Hall (2012), assesses a policy change in Sweden in 1991 that increased the academic education content of vocational schooling at the upper secondary level. Exploiting random differences in time and the regional implementation of a policy

\footnotetext{
1 See the discussion in Altonji et al. (2012).
} 


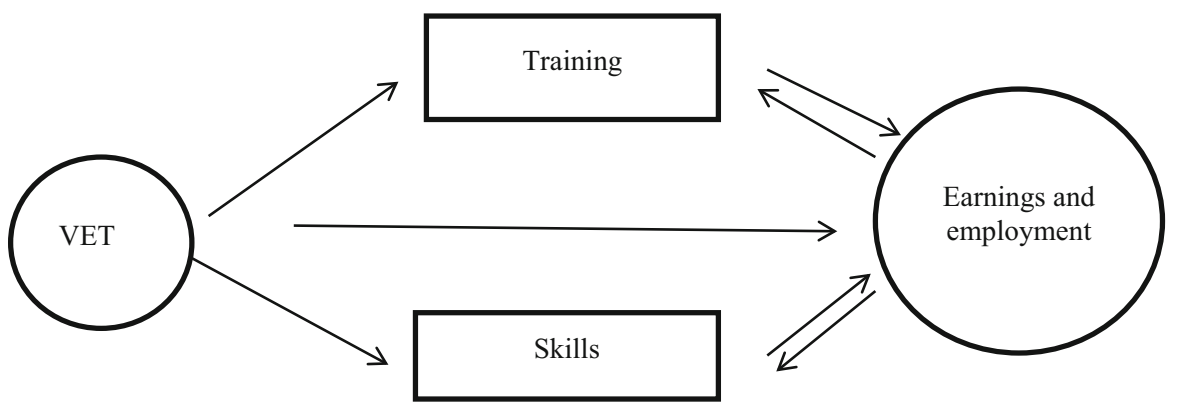

Fig. 1 The relationship between VET and labour market outcomes

pilot, she finds no effects of the policy on the wages earned up to 16 years after the beginning of secondary school.

Using a natural experiment, Malamud and Pop-Eleches (2010), find that VET graduates in Romania are significantly more likely to be employed as manual workers and craftsmen. However, there is no significant difference between VET and academic education in terms participation rates, unemployment rates, periods of non-employment, and family income. Finally, Fersterer et al. (2008), find that Austrian apprentices earn no significant wage premium when compared to other forms of school based education, such as those taking place in colleges or vocational schools.

\section{Our empirical approach}

The relationship between VET and the economic outcomes included in the PIAAC dataset is illustrated in Fig. 1. For the purposes of this paper, we consider initial education and training, whether vocational or academic, as the key input, denoted as VET, training and skills as intermediary inputs, denoted as X, and employment and wages as outcomes Y. The figure shows that the relationship between these variables is complex: we would expect, for instance, skills to influence wages and employment, but also that having a job helps maintain and accumulate skills. Similarly, individuals who have received more training may have higher wages, and better pay may induce workers to invest in further training.

Using a regression framework, the relationship between VET, $\mathrm{X}$ and $\mathrm{Y}$ can be written as

$$
\mathrm{Y}_{\mathrm{i}}=\beta_{0}+\beta_{1} \mathrm{X}_{\mathrm{i}}+\beta_{2} \mathrm{VET}_{\mathrm{i}}+\beta_{3} \mathrm{Z}_{\mathrm{i}}+\varepsilon_{\mathrm{i}}
$$

where $\mathrm{Z}$ is a vector of individual controls, VET is a dummy equal to 1 if the individual has had vocational education and to 0 otherwise, and the index $i$ is for the individual. Since intermediate inputs depend on the key input VET, we also write

$$
\mathrm{X}_{\mathrm{i}}=\gamma_{0}+\gamma_{1} \mathrm{VET}_{\mathrm{i}}+\gamma_{3} \mathrm{Z}_{\mathrm{i}}+\mathrm{v}_{\mathrm{i}}
$$


Substituting (2) into (1) we obtain

$$
\mathrm{Y}_{\mathrm{i}}=\alpha_{0}+\alpha_{1} \mathrm{VET}_{\mathrm{i}}+\alpha_{2} \mathrm{Z}_{\mathrm{i}}+\omega_{\mathrm{i}}
$$

where the marginal effect $\alpha_{1}$ in Eq. (3) is the gross effect of VET on the outcome Y, which compounds the direct effect $\beta_{2}$ and the indirect effects operating via changes in skills and training opportunities $\left(\beta_{1} \gamma_{1}\right)$. Conditional on $\mathrm{Z}$, the effect of vocational education on $\mathrm{Y}$ is given by $\alpha_{0}+\alpha_{1}$.

In this paper, we do not try to distinguish between direct and indirect effects, as Eq. (1) does, and focus instead on estimating the marginal effects $\alpha_{1}$ and $\gamma_{1}$-using Eqs. (2) and (3). Including intermediary inputs such as skills or training in the earnings or employment equation is problematic from an empirical viewpoint because skills and training are endogenous variables. These inputs depend on initial education but also reflect individual decisions taken after the end of education. Furthermore, since intermediary inputs and outcomes refer to the same time period, simultaneity issues also arise. To address these issues, we would need additional sources of exogenous variation that we cannot find in the data at hand. We therefore take a more modest route and focus only on the gross (or total) effect of vocational education on labour market outcomes. $^{2}$

How can evaluate the causal effect of VET on earnings, employment and skill proficiency? Answering this question is complicated because both education type and length, the two key attributes of any education career, are not randomly assigned to individuals, but rather are decided by students, parents and teachers. ${ }^{3}$ As suggested by standard economic theory, individuals decide the type and the quantity of education by maximizing their utility across a number of alternatives. Their optimal choice depends on preferences, cognitive abilities and attitudes, parental background and the perceived economic benefits and costs of each education career. Benefits include expected labour market returns, and costs include both the direct costs of education and the opportunity costs of delaying access to the labour market.

For given expected returns and costs of education, individuals with a preference for practical activities are more likely to opt for vocational education and individuals more attracted by abstract reasoning choose an academic track. Accordingly, while the average levels of manual dexterity and comprehension of practical problems tend to be higher among those who choose a vocational track, the average level of cognitive abilities tends to be higher among those who choose general or academic education. The asymmetric distribution of these individual characteristics is thus the result of the self-sorting of individuals across alternatives.

While preferences, abilities and attitudes determine education choices to a large extent, they also have a direct and autonomous effect on the outcomes we want to

\footnotetext{
2 Estimating Eq. (1) using standard techniques would be akin to estimating earnings functions by adding occupational dummies to the set of regressors. See Angrist and Pischke (2008), for a discussion of the problems associated with these estimates. In their recent study of vocational education in PIAAC, Lavrijsen and Nicaise (2014), overlook this problem and estimate equations similar to (1) by ordinary least squares. We report similar estimates for the sake of comparison in Sect. 5.

3 The combination of teacher recommendations, previous academic performance and parental choice varies across countries. See Checchi and Flabbi (2007), for a comparison of Germany and Italy.
} 
analyse in this paper, which include earnings, employment and skills. Therefore, the evaluation of the differential effect of vocational and academic education on these outcomes cannot rely on the simple comparison of average outcomes across individuals with different education careers.

Ideally, the causal effect of vocational education on outcomes can be identified if the individuals were randomly assigned to vocational or academic education. While random allocation is unfeasible in the real word, exogenous events (such as reforms of the school system) can produce situations equivalent to random allocation. A particularly suitable reform of vocational education has been exploited for instance by Malamud and Pop-Eleches (2010), who have found that in Romania the causal differential effect of vocational education is close to zero and that the entire difference between raw average outcomes is driven by self-sorting.

The economics of education literature has adopted several empirical strategies to identify the causal effect of vocational education, for instance by exploiting reforms which have altered either the length of compulsory education or the length of the vocational track. These exogenous changes have been used either as instruments in instrumental variable estimators or as discontinuities in regression discontinuity designs, generally in single-country settings.

In this paper we adopt a selection-on-observables strategy because (1) PIAAC has useful information to model selection into alternative education treatments; (2) our approach is multi-country and comparative; (3) suitable reforms have occurred only in a few countries, but often too early or too late to be useful, ${ }^{4}$ and their effects are difficult to use in a multi-country setup. ${ }^{5}$

In several countries, VET could be attended either at the secondary level, at the post-secondary or at the tertiary level. In the early tracking countries of Central Europe (Austria, Czech Republic and Germany), pre-vocational education is an option already at lower secondary school. Depending on the organization of education systems in each country, students are allowed to move from the academic to the vocational track and vice versa (bridging). For instance, students attending vocational education at the upper-secondary level can continue their education with a post-secondary or tertiary academic education. Generally, students are also allowed to change track before completing a given education level, possibly after passing a transfer exam. In spite of the possibility of bridging across tracks, the usual observed pattern involve initial academic education, which ends after ISCED 1 in the early tracking countries and could last until the completion of ISCED 3 in the late tracking countries, followed by a bifurcation between a vocational and an academic track, the length of witch mainly depends on the education system and on individual decisions on the optimal quantity of schooling.

\footnotetext{
4 A number of relevant reforms in Europe have simultaneously involved several aspects of vocational education, such as its length, the curriculum, teacher incentives (see the cases of Poland in 1999, Sweden in 1995, and Finland between 1972 and 1977). Since the process of reform involving vocational education has been rather continuous, as shown by CEDEFOP (2012), it is difficult to isolate the effect of one particular reform.

5 Econometric techniques which exploit policy reforms produce local effects for the sub-population of "compliers" (LATE effects). Since different reforms could impact on different groups of individuals, LATE effects may be difficult to compare across countries.
} 
In principle, students can leave education at any time after the end of compulsory education. In practice, there are three relevant exit points, at the end of compulsory education (that in many countries coincides with the completion of ISCED 2), at the end of upper-secondary education (or after one or two additional years of postsecondary non-tertiary education in the countries where this level is available) and at the end of tertiary education (ISCED 5). By combining education type and length, we define five possible education careers which fit with the schooling decisions of the vast majority of students: the early leavers, who abandon education at the end of compulsory school with at most a basic academic education (typically at ISCED 2); those who achieve an upper-secondary or post-secondary degree (ISCED 3 or 4), either vocational or academic; and those who continue studying and achieve a tertiary degree, either vocational (ISCED 5B) or academic (ISCED 5A). ${ }^{6}$

We consider the education careers available to individuals as alternative treatments in a multivalued treatment framework. We assume that individuals are exposed to four alternative treatments: (1) vocational education at the upper secondary or postsecondary level; (2) academic education at the upper secondary or post-secondary level; (3) vocational education at the tertiary level; (4) academic education at the tertiary level. We restrict our analysis to individuals who have attained at least upper secondary education because PIAAC only registers vocational education as the highest attained education at ISCED levels 3 or 4 (upper secondary or post-secondary). The excluded group, who who has completed at most ISCED 2 education, corresponds to close to $16 \%$ of the total.

Since only one treatment is observed for each individual, the remaining treatments are considered as counterfactuals. We use the inverse probability weighted regression adjusted (IPWRA) method to estimate average treatment effects (ATE), defined as the means of the difference between each treatment and the benchmark treatment. The IPWRA method yields unbiased treatment effects under the CIA (conditional independence assumption) hypothesis, which states that, conditional on a set of pre-determined variables, potential treatments are as good as randomly assigned to individuals. This assumption requires that the individual traits that have determined the choice of initial education are adequately captured by observed pre-determined variables, so that the residual variation in initial education, conditional on these characteristics, is either random or due to temporary circumstances or to factors that do not influence the outcomes of interest. We stress that we can give to estimated ATEs a causal interpretation only when the CIA hypothesis holds. A non-technical description of the methodology is provided in the "Appendix".

\section{Data}

Our sample consists of seventeen countries with reliable information on vocational education at ISCED levels 3-5. They are: Australia, Austria, Canada, Czech Repub-

\footnotetext{
6 In countries where level ISCED 5B is available, the majority of students come from the vocational track, while ISCED 5A is attended mainly by students coming from an academic track. Thus ISCED 5 can often be intended as a continuation of the path started at ISCED 3 (or earlier).
} 
lic, Estonia, Finland, France, Germany, Ireland, Japan, Korea, Netherlands, Norway, Poland, Spain, United Kingdom and United States. ${ }^{7}$ PIAAC includes individuals aged between 16 and 65 . We restrict our sample by excluding those aged below 25 , who are likely to be still in school. We also retain individuals aged 60-65 when considering proficiency in fundamental skills and skill use, but exclude them when examining the effects of VET on labour market outcomes, because of the selection problems associated to retirement.

We exclude from our final sample the individuals who have completed relatively uncommon education careers. Possible education careers combine vocational education at ISCED 3 or 4, academic education at ISCED 3 or 4, vocational education at ISCED 5 and academic education at ISCED 5. While in all the countries in our sample there is a significant proportion of individuals with vocational education at ISCED 3-4 or with academic education at ISCED 5, vocational education at ISCED 5 is relatively less frequent in Canada, the Czech Republic and Poland, where it accounts for $<5 \%$ of the sample. Academic education at ISCED 3-4 is also relatively uncommon in Austria and Germany. As a rule, when the share of individuals attaining a particular education career is below $5 \%$ in a country, we remove from the analysis the treatment and the corresponding observations for that country. The final sample consists of about 73 thousand individuals, distributed across countries and education careers as in Table 1.

\section{The effect of vocational education on skills and competences}

Is the contribution of vocational education to adult proficiency in basic skills (literacy, numeracy and ICT skills) larger or smaller compared to that provided by academic education? This question is relevant because a proper command of basic skills is a necessary condition for an active and independent life, for updating and extending advanced skills and competences and for remaining competitive in the labour market, but also for being able to access administrative, financial and health services and to profit from the broad range of advantages offered by the new technologies. Literacy and numeracy are often described as "basic" skills, because they provide a "foundation" on which the development of other competencies rests (OECD 2013, p. 19).

In PIAAC, literacy is defined as the ability to understand, evaluate, use and engage with written texts to participate in society, to achieve one's goals, and to develop one's knowledge and potential. Literacy proficiency is assessed by asking subjects to analyse a variety of written texts. Numeracy is defined as the ability to access, use, interpret and communicate mathematical information and ideas in order to engage in and manage the mathematical demands of a range of situations in adult life. To assess numeracy proficiency, individuals are asked questions involving numerical computation, geometrical representation, data manipulation, represented either as texts or graphically.

Problem solving in technology-rich environments (simply problem solving or PSTRE hereafter) is defined as the ability to use digital technology, communication

\footnotetext{
7 The estimates based on seventeen countries were performed at the OECD using internal data and codes prepared by the authors.
} 
Table 1 The sample used in this study. Number of individuals. Source: PIAAC data

\begin{tabular}{|c|c|c|c|c|c|}
\hline Country & $\begin{array}{l}\text { Vocational } \\
\text { education } \\
\text { at ISCED } \\
3-4\end{array}$ & $\begin{array}{l}\text { Academic } \\
\text { education } \\
\text { at ISCED } \\
3-4\end{array}$ & $\begin{array}{l}\text { Vocational } \\
\text { education } \\
\text { at ISCED } \\
5\end{array}$ & $\begin{array}{l}\text { Academic } \\
\text { education } \\
\text { at ISCED } \\
5\end{array}$ & Total \\
\hline Australia & 1243 & 576 & 652 & 1633 & 4104 \\
\hline Austria & 1931 & & 323 & 488 & 2742 \\
\hline Canada & 2878 & 3586 & & 9496 & 15,960 \\
\hline Czech Republic & 2431 & 158 & & 823 & 3412 \\
\hline Estonia & 1495 & 1028 & 906 & 1333 & 4762 \\
\hline Finland & 1273 & 278 & 674 & 1173 & 3398 \\
\hline France & 1590 & 542 & 626 & 1051 & 3809 \\
\hline United Kingdom & 503 & 1468 & 758 & 1931 & 4660 \\
\hline Germany & 1959 & & 552 & 906 & 3417 \\
\hline Ireland & 900 & 822 & 752 & 1141 & 3615 \\
\hline Japan & 507 & 880 & 910 & 1117 & 3414 \\
\hline Korea & 833 & 1097 & 922 & 1325 & 4177 \\
\hline Netherlands & 1037 & 315 & 155 & 1122 & 2629 \\
\hline Norway & 1160 & 370 & 181 & 1421 & 3132 \\
\hline Poland & 2092 & 409 & & 1462 & 3963 \\
\hline Spain & 131 & 759 & 422 & 1071 & 2383 \\
\hline United States & 323 & 1323 & 343 & 1203 & 3192 \\
\hline Total & 22,286 & 13,611 & 8176 & 28,696 & 72,769 \\
\hline
\end{tabular}

tools and networks to acquire and evaluate information, communicate with others and perform practical tasks. The assessment of problem solving proficiency focuses on the abilities to solve problems for personal, work and civic purposes by setting up appropriate goals and plans, and accessing and making use of information through computers and computer networks.

In this section, our sample includes individuals aged between 25 and 64. All seventeen countries assess literacy and numeracy proficiency. Problem solving, instead, is measured only in fifteen countries, with the exclusion of Cyprus, Italy, France and Spain.

Skill proficiency is measured over a continuum bounded between 0 and 500. Higher values represent higher proficiency levels. An individual assigned a given proficiency level $P$ has a $67 \%$ probability of responding correctly to the questions designed to have a difficulty level equal to $P$, a much higher probability of responding correctly to question less difficult than $P$, and a much lower probability of responding correctly to questions more difficult than $P$.

Differently from literacy and numeracy, the PIAAC assessment of proficiency in problem solving in technology rich environments (PSTRE) has been possible only for the individuals with had at least basic competencies in computer use, being the test computed based. Problem solving has been assessed only for those who reported 
having some preliminary computer experience, agreed in performing a computer based assessment (CBA) of their skills and passed a preliminary evaluation of their ICT competences. $^{8}$

Overall, the evaluation of problem solving proficiency has been possible for $81 \%$ of our sample. For the remaining 19\%, PSTRE proficiency is missing. There is heterogeneity in the proportion of missing values in this test across countries and educational careers (though not between genders). Poland, Japan, Estonia, Ireland and Korea have the highest rates of missing data as opposed to the Netherlands, the U.S., Canada and Norway, where the proportion of missing data is smallest.

Missing values are more frequent among individuals with vocational education at ISCED 3-4, followed by individuals with academic education at ISCED 3-4. They are less frequent at ISCED 5. Overall, the differential missing rate between vocational and academic education is relatively small when taken at the same ISCED level, while we observe large differences across education levels. Major exceptions to this pattern are Poland, the Czech Republic and Finland at ISCED 3-4 and Japan and Estonia at ISCED 5.

Missing values are due both to lack of ICT competences (including lack of experience and failure in core ICT tests) and to the refusal to undertake a computer-based assessment. Refusal of CBA is more frequent than lack of ICT competences in many countries, but the relative importance of each explanation does not depend on the educational career. For this reason and given that the lack of ICT competence is likely to induce refusal of CBA, in the following analysis we will treat PSTRE proficiency as a single outcome, without distinguishing between the two sources.

\subsection{Literacy}

We average country-specific ATEs_-defined as differences between population means of potential outcomes-over our sample of countries and report these mean differential effects in Table 2. When averaging, each country-specific ATE is weighted by the inverse of its variance, so that more precisely estimated ATEs weight more. ${ }^{9}$ We report ATEs separately by gender and for the entire sample (individuals aged between 25 and 64), for the subsample of those aged between 25 and 44 and the difference in ATEs between individuals aged 45-64 and individuals aged 25-44.

For both genders, we observe that vocational education is not as effective as academic education in promoting literacy proficiency. The differences in ATEs between younger and senior individuals are small and generally non-statistically significant. ${ }^{10}$ Considering education at ISCED 3-4 (column 1) and the entire sample, we find that literacy proficiency is about $2 \%$ lower among individuals who completed a voca-

\footnotetext{
8 Individuals were required to undertake two core ICT tests. Those who failed the first test were assigned to a paper-based evaluation, including only the assessment of literacy and numeracy proficiency. Those who passed the first test but failed the second were evaluated only on a sub-set of items.

9 Country specific estimates are shown in Brunello and Rocco (2015).

10 There is a significant (at 95\%) difference in ATEs between the two age groups only for females and when we compare individuals with vocational education at ISCED 5 with those with academic education at the same ISCED level.
} 
Table 2 Aggregated average treatment effects. Dependent variable: log literacy score. Source: Calculations based on PIAAC data

\begin{tabular}{lll}
\hline & $\begin{array}{l}\text { Vocational ISCED 3-4 versus } \\
\text { academic ISCED 3-4 }\end{array}$ & $\begin{array}{l}\text { Vocational ISCED 5 versus } \\
\text { academic ISCED 5 }\end{array}$ \\
\hline Males & & \\
Age 25-64 & $-0.022^{* * *}$ & $-0.059^{* * *}$ \\
& $(0.003)$ & $(0.003)$ \\
Age 25-44 & $-0.032^{* * *}$ & $-0.059^{* * *}$ \\
& $(0.004)$ & $(0.004)$ \\
Gap between age 45-64 and & $0.008^{*}$ & -0.001 \\
age 25-44 & $(0.005)$ & $(0.006)$ \\
Females & & $-0.057^{* * *}$ \\
Age 25-64 & $-0.020^{* * *}$ & $(0.002)$ \\
Age 25-44 & $(0.003)$ & $-0.058^{* * *}$ \\
Gap between age 45-64 and & $-0.019^{* * *}$ & $(0.003)$ \\
age 25-44 & $(0.004)$ & $0.006^{* *}$ \\
& -0.001 & $(0.005)$ \\
\hline
\end{tabular}

Standard errors within parentheses. $* * *, * * *$ statistical significance at the 10,5 and $1 \%$ level of confidence

tional track (2.2\% lower among males and $2.0 \%$ lower among females). Turning to ISCED 5, literacy proficiency is 5.9\% lower for males (resp. 5.7\% lower for females) with vocational education (column 2).

\subsection{Numeracy and problem solving}

We present our estimates of the ATEs involving vocational and academic education at different ISCED levels in Table 3 for numeracy and in Table 4 for problem solving. Unsurprisingly, the patterns described for literacy fit remarkably well with those of both these skills. The size of the effects is largely comparable, especially at the secondary and post-secondary non-tertiary level (column 1 of Tables 3, 4). Also, the distribution of the effects across genders almost perfectly mirrors that observed for literacy.

Especially among females, there is a moderate gradient across domains in the effects. The estimated ATEs on problem solving are the smallest in absolute value, followed by those on literacy and finally by those on numeracy. Consequently, the difference between ATEs is relatively large if we contrast numeracy and problem solving. Indeed, the relative effect of vocational education at the tertiary level (compared to academic education at the same level) is that of reducing proficiency in problem solving by $4.4 \%$ among males and $4.7 \%$ among females. The corresponding effect on 
Table 3 Aggregated average treatment effects. Dependent variable: log numeracy score. Source: Calculations based on PIAAC data

\begin{tabular}{lll}
\hline & $\begin{array}{l}\text { Vocational ISCED 3-4 versus } \\
\text { academic ISCED 3-4 }\end{array}$ & $\begin{array}{l}\text { Vocational ISCED 5 versus } \\
\text { academic ISCED 5 }\end{array}$ \\
\hline Males & & \\
Age 25-64 & $-0.019^{* * *}$ & $-0.067^{* * * *}$ \\
& $(0.003)$ & $(0.003)$ \\
Age 25-44 & $-0.030^{* * *}$ & $-0.066^{* * *}$ \\
& $(0.004)$ & $(0.004)$ \\
Gap between age 45-64 and & 0.008 & -0.003 \\
age 25-44 & $(0.006)$ & $(0.006)$ \\
Females & & $-0.070^{* * * *}$ \\
Age 25-64 & $-0.029^{* * *}$ & $(0.003)$ \\
& $(0.003)$ & $-0.070^{* * * *}$ \\
Age 25-44 & $-0.028^{* * *}$ & $(0.003)$ \\
Gap between age 45-64 and & $(0.004)$ & 0.002 \\
age 25-44 & -0.004 & $(0.005)$ \\
\hline
\end{tabular}

See Table 2

numeracy proficiency is larger and equal to 6.7 and $7 \%$ respectively (column 2 in Tables 3, 4). ${ }^{11}$

\subsection{Patterns in the ATEs}

We analyse the heterogeneity of ATEs across countries by regressing ATEs on a set of country specific characteristics, including indicators of the size and characteristics of vocational education in each country, labour market indicators and per-capita real GDP. In these estimates, we pool ISCED levels and types of skill. Since the regressors of interest vary at the country level, standard errors are clustered by country. In the regressions, each ATE is weighted by the inverse of its variance. Results are reported in Table 5 for males, females and for both genders combined. ${ }^{12}$

The estimates indicate that the negative gap in proficiency associated to vocational education is larger at ISCED 5 than at ISCED 3-4 by about 3\% points, slightly larger

\footnotetext{
11 Estimates of the effects of VET on problem solving should be interpreted with care for countries such as Poland, Japan, Estonia, Ireland and Korea, where the proportion of missing data on PSTRE proficiency is relatively high. To account for the role of missing data, we report in Brunello and Rocco (2015), the estimates obtained when the outcome variable is an indicator of missing PSTRE assessment (a dummy which takes the value 1 if the individual either lacks basic ICT skills or he/she refuses to take computerbased assessment and 0 otherwise). This outcome can also be viewed as an indicator of ICT illiteracy. At ISCED 3-4, we observe that vocational education has no significant effect on the probability of being an ICT illiterate at ISCED 3-4 for both. When we consider higher education-ISCED 5-the evidence suggests that vocational education increases the probability of ICT illiteracy among males and females.

12 We also control for differences in missing values in the PSTRE evaluation.
} 
Table 4 Aggregated average treatment effects. Dependent variable: log problem solving score. Source: Calculations based on PIAAC data

\begin{tabular}{lll}
\hline & $\begin{array}{l}\text { Vocational ISCED 3-4 versus } \\
\text { academic ISCED 3-4 }\end{array}$ & $\begin{array}{l}\text { Vocational ISCED 5 versus } \\
\text { academic ISCED 5 }\end{array}$ \\
\hline Males & & \\
Age 25-64 & $-0.018^{* * * *}$ & $-0.044^{* * *}$ \\
& $(0.003)$ & $(0.003)$ \\
Age 25-44 & $-0.025^{* * *}$ & $-0.043^{* * *}$ \\
& $(0.004)$ & $(0.003)$ \\
Gap between age 45-64 and & 0.000 & -0.003 \\
age 25-44 & $(0.006)$ & $(0.005)$ \\
Females & & $-0.047^{* * *}$ \\
Age 25-64 & $-0.023^{* * *}$ & $(0.002)$ \\
& $(0.003)$ & $-0.049^{* * *}$ \\
Age 25-44 & $-0.021^{* * *}$ & $(0.003)$ \\
Gap between age 45-64 and & $(0.004)$ & $0.009^{* * *}$ \\
age 25-44 & -0.005 & $(0.005)$ \\
\hline
\end{tabular}

see Table 2

for numeracy and slightly smaller for problem solving (compared to the other two domains). There is little difference across genders. While the negative gap increases with the proportion of students attending a vocational track, it is invariant with respect to country differences in the presence of combined schooling and work VET programs. There is evidence (especially among males) that higher per capita income contributes to reduce the gap. Finally, neither the unemployment rate nor the degree of employment protection are significantly associated with ATEs. ${ }^{13}$

\subsection{Summary}

The analysis of proficiency in basic skills reveals that vocational education is generally not as effective as academic education. This is true for both genders and, in spite of some heterogeneity, for all countries. The gap is larger for tertiary education (ISCED 5) in countries where the share of vocational students is higher.

The relative dominance of academic curricula is a source of concern especially when the use of ICT skills are considered, given that computer-related technologies are spreading to all provinces of economic and social activities. It is also a matter of concern that those with vocational education appear to be not as ready to learn as those with a more academic curriculum, especially at higher levels of education. For a policy perspective, however, one might ask to what extent these attitudes are the

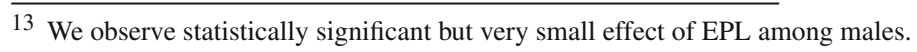


Table 5 Partial correlations between estimated ATEs and country specific effects

\begin{tabular}{|c|c|c|c|}
\hline \multirow[t]{2}{*}{ Variables } & (1) & $(2)$ & (3) \\
\hline & Males & Females & All \\
\hline ISCED 5 dummy & $\begin{array}{l}-0.035^{* * *} \\
(0.010)\end{array}$ & $\begin{array}{l}-0.030 * * \\
(0.013)\end{array}$ & $\begin{array}{l}-0.032 * * * \\
(0.009)\end{array}$ \\
\hline Female dummy & & & $\begin{array}{l}0.000 \\
(0.004)\end{array}$ \\
\hline Share with vocational education & $\begin{array}{l}-0.009 * * * \\
(0.002)\end{array}$ & $\begin{array}{l}-0.011 * * \\
(0.004)\end{array}$ & $\begin{array}{l}-0.010 * * * \\
(0.002)\end{array}$ \\
\hline Vocational programs combining school and work & $\begin{array}{l}0.001 \\
(0.014)\end{array}$ & $\begin{array}{l}0.003 \\
(0.010)\end{array}$ & $\begin{array}{l}0.003 \\
(0.009)\end{array}$ \\
\hline Unemployment rate & $\begin{array}{l}-0.000 \\
(0.001)\end{array}$ & $\begin{array}{l}-0.001 \\
(0.001)\end{array}$ & $\begin{array}{l}-0.001 \\
(0.001)\end{array}$ \\
\hline Employment protection legislation & $\begin{array}{l}-0.006 * * \\
(0.003)\end{array}$ & $\begin{array}{l}0.003 \\
(0.005)\end{array}$ & $\begin{array}{l}-0.003 \\
(0.003)\end{array}$ \\
\hline Log real GDP per-capita & $\begin{array}{l}0.013 * * * \\
(0.002)\end{array}$ & $\begin{array}{l}0.001 \\
(0.004)\end{array}$ & $\begin{array}{l}0.006^{* * * *} \\
(0.002)\end{array}$ \\
\hline \multicolumn{4}{|l|}{ Domain } \\
\hline \multicolumn{4}{|l|}{ Reference: Literacy } \\
\hline Numeracy & $\begin{array}{l}-0.002 \\
(0.002)\end{array}$ & $\begin{array}{l}-0.009 * * * \\
(0.003)\end{array}$ & $\begin{array}{l}-0.006^{* * * *} \\
(0.004)\end{array}$ \\
\hline Problem solving & $\begin{array}{l}0.014 * * * \\
(0.005)\end{array}$ & $\begin{array}{l}0.009 * * * \\
(0.003)\end{array}$ & $\begin{array}{l}0.011 * * * \\
(0.004)\end{array}$ \\
\hline Differential missing rate in problem solving & $\begin{array}{l}-0.112^{*} \\
(0.063)\end{array}$ & $\begin{array}{l}-0.111^{* * *} \\
(0.046)\end{array}$ & $\begin{array}{l}-0.116^{* * * *} \\
(0.041)\end{array}$ \\
\hline Constant & $\begin{array}{l}-0.021 \\
(0.012)\end{array}$ & $\begin{array}{l}-0.000 \\
(0.014)\end{array}$ & $\begin{array}{l}-0.009 \\
(0.010)\end{array}$ \\
\hline Observations & 75 & 75 & 150 \\
\hline R-squared & 0.600 & 0.447 & 0.490 \\
\hline
\end{tabular}

Standard errors within parentheses clustered by country. *** $p<0.01$, ** $p<0.05, * p<0.1$. ATE for proficiency in literacy, numeracy and problem solving are pooled in the dataset. The variable "differential missing rate in problem solving" is obtained as the difference between the proportion of individuals with vocational education who failed to be tested for PSTRE and the corresponding proportion among individuals with academic education, by level of education, country and gender. Source: calculations based on PIAAC data

outcome of the type of education (vocational or academic), or rather a factor explaining why individuals choose vocational rather than academic tracks. If readiness to learn develops early on in the life of individuals and persists over time, failure to control for individual differences in this attitude may violate our "conditional independence assumption" and bias our estimated ATEs. Our defence to this objection is that, as long as readiness to learn depends on parental education and on the availability of books at home, our ability to control for these differences ensures that assignment to treatment remains as good as random. We stress that only in this case we are entitled 
to interpret our findings on readiness to learn as reflecting the type of skills learnt in vocational and academic curricula.

The result that VET does not perform as well as academic education in literacy, numeracy and skill use may also be the natural consequence of the fact that these skills are to a large extent "academic" skills. If vocational education excels in the production of "practical" or "occupation-specific" skills, the fact that these skills are not measured by PIAAC should warn the reader against rushing to easy conclusions. This concern is at the basis of recent efforts to measure at least some of these skills (see Baethge and Arends 2009), although this is clearly a difficult task.

\section{The effects of vocational education on labour market outcomes}

In this section we examine the effects of vocational education on labour market outcomes. We compare four treatments, vocational and academic education at ISCED level 3-4 (upper secondary or post-secondary education), and vocational and academic education at ISCED 5 (tertiary education). Selected outcomes include the hourly wage and current employment status. Our sample consists of the seventeen countries for which we have data and where vocational education can be clearly identified.

Our measure of earnings is hourly earnings including bonuses for wage and salary earners. PIAAC data include also broader measures of earnings, which encompass the earnings of the self-employed. Given their low reliability, however, we ignore these measures in the current paper. Employment-inclusive of self-employment-is one among alternative current labour market statuses at the time of the survey, which include also unemployment and out of the labour force.

\subsection{Earnings}

We restrict our sample to individuals aged 25-59, who are likely to have completed their education and to be only marginally affected by retirement. We use the IPWRA method to estimate average treatment effects for the four relevant treatments (vocational ISCED 3-4, academic ISCED 3-4, vocational ISCED 5 and academic ISCED 5). For most countries in our sample we use the publicly available hourly data on hourly wages. For the five countries where hourly wages are not publicly available, the relevant estimates are provided by the OECD.

Table 6 presents the estimated effects of education type and level on log hourly earnings, separately for males and females. The table shows average relative effects across countries, obtained by weighting each estimated country specific effect with the reciprocal of its variance, so that more precise estimates weigh more. Consider first education at ISCED level 3 or 4 . Estimates in column (1) suggest that vocational education does not perform as well as academic education. The negative gap is smaller for men- $<2 \%$ points and not statistically significant - than for women, who suffer a $4.8 \%$ negative and statistically significant gap.

At the tertiary level the negative gap widens, ranging from $19 \%$ for men to $21.7 \%$ for women results [see column (2) in the Table]. The second row in the table reports for both genders the differences in average treatment effects of vocational with respect 
Table 6 Average treatment effects of vocational education relative to academic education. Dependent variable: log hourly earnings. Source: Calculations based on PIAAC data

\begin{tabular}{lll}
\hline & $\begin{array}{l}\text { Vocational ISCED 3-4 versus } \\
\text { academic ISCED 3-4 }\end{array}$ & $\begin{array}{l}\text { Vocational ISCED 5 versus } \\
\text { academic ISCED 5 }\end{array}$ \\
\hline Males & & \\
Age 25-59 & -0.013 & $-0.190^{* * * *}$ \\
& $(0.012)$ & $(0.012)$ \\
Age 25-44 & -0.003 & $-0.182^{* * *}$ \\
& $(0.014)$ & $(0.013)$ \\
Gap between age 45-59 and & $-0.052^{* * *}$ & $-0.031^{* * *}$ \\
age 25-44 & $(0.012)$ & $(0.012)$ \\
Females & & $-0.217^{* * *}$ \\
Age 25-59 & $-0.048^{* * *}$ & $(0.010)$ \\
Age 25-44 & $(0.011)$ & $-0.204^{* * * *}$ \\
Gap between age 45-59 and & $-0.043^{* *}$ & $(0.012)$ \\
age 25-44 & $(0.013)$ & $-0.063^{* * *}$ \\
\hline
\end{tabular}

Standard errors within parentheses. One, two and three stars for statistical significance at the 10,5 and $1 \%$ level of confidence

to academic education for the sub-group of individuals aged 25-44. The third row reports instead the estimated differential ATE between the group aged 45-59 and the younger age group.

The large gap in hourly earnings at the tertiary level could be driven by the fact that college graduates are more likely to access top paying occupations. However, part of the gap could be generated by our failure to properly controls for differences in individual ability. If the ablest individuals sort into higher academic education, such failure bias the treatment effect of vocational education downward.

By adding the numbers in the second row to the numbers in the third row one can get the estimated differences in average treatment effects for the older age group. The table shows that the negative effect of vocational education is stronger among older males and females. To illustrate, the earnings of older male workers with vocational education at ISCED 3-4 are 5.5\% lower than with academic education at ISCED 3-4. This negative gap is equal to $6.7 \%$ for older females.

The finding that the negative gap is generally larger for the older than for the younger age group does not necessarily imply that this gap widens with age, as we are comparing different cohorts rather than individuals at different points of their age profiles. Since it is impossible with the cross section data at hand to distinguish between age and cohort effects, the effects of age on estimated returns by education type cannot be discussed here.

We estimate country-specific average treatment effects between vocational and academic education, pool the estimated differences in returns for each ISCED level across genders and regress them on relative supply, the difference in the average 
Table 7 Partial correlations between estimated differences in log hourly earnings and country specific effects. Both genders and ISCED levels. Dependent variable: estimated differences in log hourly earnings and in employment. Source: Calculations based on PIAAC data

\begin{tabular}{lll}
\hline & Relative hourly wage & Relative employment \\
\hline ISCED 5 dummy & $-0.153^{* * * *}$ & $-0.034^{*}$ \\
& $(0.037)$ & $(0.017)$ \\
Female dummy & $-0.029^{* *}$ & -0.008 \\
& $(0.010)$ & $(0.011)$ \\
Share with vocational education & -0.210 & -0.080 \\
& $(0.121)$ & $(0.052)$ \\
Vocational programs combining school and work & 0.048 & -0.010 \\
& $(0.028)$ & $(0.010)$ \\
Average years of education & $0.020^{*}$ & 0.006 \\
& $(0.010)$ & $(0.006)$ \\
Constant & 0.037 & $0.043^{* *}$ \\
Observations & $(0.044)$ & $(0.017)$ \\
R-squared & 58 & 58 \\
\hline
\end{tabular}

see Table 6

years of education and a dummy indicating whether the vocational system in the country has programs that combine school and work, using as weights the reciprocal of the variance of estimated returns, so that more precise estimates receive a higher weight. ${ }^{14}$

As shown in the first column of Table 7, there is some evidence that differences in returns correlate negatively with relative supply and positively with differences in the average length of education programs. There is also some evidence that wage returns associated to vocational education are relatively higher in countries with programs that combine school and work, although all these estimated effects are not statistically significant at conventional levels. We hasten to stress that this exercise does not uncover causal relationships and should therefore be interpreted with caution.

\subsection{Employment}

We have documented so far that vocational education-both at ISCED 3-4 and at ISCED 5 levels-makes a difference with respect to hourly earnings, and that this difference can be sizeable. Next, we document the effects that this type of education has on current employment status.

\footnotetext{
14 Standard errors are clustered by country, because the explanatory variables vary at this level. However, we warn the reader that with are relatively small number of clusters (15 in our case) standard error estimates could be downward biased (see Cameron amd Miller 2013).
} 
Table 8 Average treatment effects of vocational education relative to academic education. Dependent variable: current employment status. Source: Calculations based on PIAAC data

\begin{tabular}{lll}
\hline & $\begin{array}{l}\text { Vocational ISCED 3-4 versus } \\
\text { academic ISCED 3-4 }\end{array}$ & $\begin{array}{l}\text { Vocational ISCED 5 versus } \\
\text { academic ISCED 5 }\end{array}$ \\
\hline Males & & \\
Age 25-59 & $0.022^{* * *}$ & $-0.014^{* *}$ \\
& $(0.008)$ & $(0.006)$ \\
Age 25-44 & $0.026^{* * *}$ & -0.004 \\
& $(0.009)$ & $(0.008)$ \\
Gap between age 45-59 and & $-0.025^{* * *}$ & $-0.034^{* * *}$ \\
age 25-44 & $(0.008)$ & $(0.006)$ \\
Females & & $-0.027 * * *$ \\
Age 25-59 & $0.019^{*}$ & $(0.008)$ \\
& $(0.010)$ & -0.014 \\
Age 25-44 & 0.014 & $(0.009)$ \\
Gap between age 45-59 and & $(0.013)$ & $-0.018^{* * *}$ \\
age 25-44 & 0.006 & $(0.008)$ \\
\hline
\end{tabular}

see Table 6

As in the case of earnings, we estimate average treatment effects for each of the four available treatments and compute average differences in employment probabilities between vocational and academic education at both ISCED levels. Our estimates are reported in Table 8, which is organized as Table 6. The numbers reported in the table should be interpreted as percentage differences between employment probabilities. We find that vocational education at ISCED 3-4 level increases employment probability compared to academic education at the same ISCED level. When compared to tertiary academic education, however, the advantage of vocational education (at the same ISCED level) disappears and turns into a disadvantage that is especially large among females $(-2.7 \%$ points).

Our estimates also reveal that almost any employment advantage for those with vocational education tends to disappear in the older age group. If one adds the second and the third row of the table-for each gender-the percentage gap

Table 9 Probability of being NEET by gender, age and education type. Raw data. Source: Our computations using PIAAC data

\begin{tabular}{lllll}
\hline & Males & Females & Age group 25-44 & Age group 45-59 \\
\hline Vocational ISCED 3-4 & 0.72 & 0.75 & 0.67 & 0.81 \\
Academic ISCED 3-4 & 0.63 & 0.73 & 0.62 & 0.8 \\
Vocational ISCED 5 & 0.53 & 0.61 & 0.57 & 0.64 \\
Academic ISCED 5 & 0.42 & 0.5 & 0.41 & 0.59 \\
\hline
\end{tabular}


in employment probabilities turns negative in all cases with the single exception of the comparison between vocational and academic ISCED 3-4 education for females.

Among those not currently employed, we can distinguish in these data between those who have been in education and training in the past 12 months and those who haven't (NEET). Table 9 shows the percentage of NEET among those not currently employed by gender, age group and type of education. We find that, for each level of education, vocational education is associated to a higher probability of being NEET. This probability increases with age for all education types, possibly because of early retirement patterns and other labour force exits.

Current employment status only partly captures employability associated to the level and type of education, because individuals who are currently employed may have experienced previous periods of joblessness. We therefore supplement the existing evidence with information on the total number of years of work experience acquired during a working life, which is available in PIAAC only for thirteen countries in our sample (missing for Austria, Germany, Canada and the US). We divide years by age minus 14, assuming that most labour market history starts after that age. Table 10 presents our estimates for the full sample and for the two sub-samples of younger and older individuals.

Focusing on all age groups, our results clearly suggest that vocational education increases the amount of time spent at work relative to academic education. When we consider vocational and academic education at the same ISCED level, involving similar numbers of years spent at school, we find that the gap between vocational and

Table 10 Average treatment effects of vocational education relative to academic education. Dependent variable: years of work/(age-14). Source: Calculations based on PIAAC data

\begin{tabular}{lll}
\hline & $\begin{array}{l}\text { Vocational ISCED 3-4 versus } \\
\text { academic ISCED 3-4 }\end{array}$ & $\begin{array}{l}\text { Vocational ISCED 5 versus } \\
\text { academic ISCED 5 }\end{array}$ \\
\hline Males & $0.057^{* * *}$ & $0.122^{* * *}$ \\
Age 25-59 & $(0.010)$ & $(0.010)$ \\
Age 25-44 & $0.069^{* * *}$ & $0.169^{* * *}$ \\
& $(0.013)$ & $(0.013)$ \\
Gap between age 45-59 and & $-0.042^{* * *}$ & $-0.107^{* * *}$ \\
age 25-44 & $(0.010)$ & $(0.010)$ \\
Females & & $0.073^{* * *}$ \\
Age 25-59 & 0.008 & $(0.010)$ \\
& $(0.014)$ & $0.126^{* * *}$ \\
Age 25-44 & 0.010 & $(0.014)$ \\
Gap between age 45-59 and & $(0.018)$ & $-0.136^{* * *}$ \\
age 25-44 & -0.010 & $(0.010)$ \\
\hline
\end{tabular}

see Table 6 
Table 11 Average treatment effects of vocational education relative to academic education, depurated from the effect due to different years of school between treatment and counterfactual. Dependent variable: log years of work. With additional controls for years of schooling. Source: Calculations based on PIAAC data

\begin{tabular}{lll}
\hline & $\begin{array}{l}\text { Vocational ISCED 3-4 versus } \\
\text { academic ISCED 3-4 }\end{array}$ & $\begin{array}{l}\text { Vocational ISCED 5 versus } \\
\text { academic ISCED 5 }\end{array}$ \\
\hline Males & & \\
Age 25-59 & $0.033^{* * *}$ & $0.069^{* * *}$ \\
& $(0.004)$ & $(0.004)$ \\
Females & & $0.037^{* * *}$ \\
Age 25-59 & 0.006 & $(0.004)$ \\
\hline
\end{tabular}

see Table 6

academic education is 5.7 and $12.2 \%$ points for males and 0.8 and $7.3 \%$ points for females.

To some extent, these positive gaps may depend on the fact that, even controlling for ISCED level, those in academic school tend to stay longer in school, and therefore have less time to spend in the labour market. To check this, we have depurated countyspecific ATEs from the effect due to the differential numbers of years of schooling between each treatment and counterfactual in the aggregation procedure. As shown in Table 11, the estimated gaps decline in most cases, especially among females. The positive premium associated to vocational education, however, remains, especially among males.

\subsection{Summary}

Our investigation of the labour market payoffs to vocational and academic education at ISCED 3-4 (upper secondary and post-secondary education) suggests that individuals with vocational education earn slightly lower hourly earnings and enjoy a mildly higher probability of being currently employed than their more academically oriented counterparts. The higher probability of current employment of the vocationally trained is reinforced by their higher share of completed working life spent in paid employment, even after controlling for the length of education programs.

When we consider vocational and academic education at the tertiary level (ISCED 5), we find evidence that individuals with the former type of education have significantly lower hourly earnings and a slightly lower probability of being current employed than those with a more academic education. Independently of the ISCED level, we find that vocational graduates who are not currently employed are more likely to be NEET. When we consider the time spent in a paid job since leaving school, individuals with tertiary vocational education retain a clear advantage with respect to those with a more academic education.

To obtain a partial indication of whether the effect of initial vocational education (IVET) on labour market outcomes is mediated by workers' cognitive skills, we have conditioned for literacy and numeracy test scores, neglecting the fact that these are 
endogenous variables. The effect of IVET on earnings estimated using the IPWRA method becomes smaller in absolute value for both genders and levels of education (ISCED 3-4 and ISCED 5), but remains negative and always statistically significant, with the exception of males with ISCED 3-4. The effect of IVET on employment is virtually unchanged for both genders with ISCED 5, and increases for both genders with ISCED 3-4 level.

We also investigate whether investing in continuous vocational education and training, either on the job or off the job (CVET), mediates the effect of IVET on earnings and employment. By including CVET among the controls, we obtain that the estimated effects of IVET on earnings and employment remain constant for both genders and education levels. Only the effect of IVET on employment for females with ISCED 5 level becomes smaller in absolute level and statistically insignificant. We conclude that the effect of IVET on labour market outcomes is mediated by the effects of IVET on cognitive skills rather than on CVET.

Our results on the relative employability of individuals with vocational education clearly reflect the current economic situation, and the current balance of demand and supply of skills. But what about future demand developments? Is the number of jobs requiring vocational skills expected to decline or to increase in the future? Statistics Norway (2013), has produced projections up to 2030 on the expected labour demand by type of education. These projections show that the relative number of jobs requiring upper secondary vocational education are likely to grow faster than supply in the near future, especially in the health care industry-because of the progressive ageing of the population, with potentially positive developments for the earnings and employability of those having the required skills. Of course, if the demand for jobs requiring academic tertiary education grows even faster, thereby offering better earnings and employment prospects, enrolment in vocational education may decline even in the presence of favourable demand developments.

\section{Conclusions}

We have shown that vocational education does not perform as well as academic education both in labour market outcomes and in the level of basic skills, including literacy and numeracy. This is especially true for higher education. Only at the upper secondary or post-secondary level does vocational education perform slightly better than academic education in the probability of being currently employed as well as in the time spent in paid employment, although the differences we find are small.

Should then vocational education be reduced in favour of more academic curricula? One might say that the answer is partially provided by the recent evolution of vocational curricula in many countries, which are characterized by increasing emphasis on more academic education. Our own view is more nuanced.

First of all, this paper provides substantial information on the benefits of vocational and academic education, but has very little to say on costs. Yet, individual decisions to undertake vocational or academic education depend both on benefits and on costs. Although academic education provides higher earnings, higher skills proficiency and better non-monetary outcomes, it could also have higher costs for 
some individuals, who may find that a vocational curriculum, if available, is privately optimum.

Beside direct and opportunity costs, an important component of the private cost of education is the disutility of the effort required to complete it, which depends on several factors, including the composition of the ability portfolio an individual is endowed with. On the one hand, individuals with higher cognitive ability, who often come from better educated families and environments, are advantaged in acquiring academic education and are likely to have a lower cost of effort when engaging in this type of education. On the other hand, individuals with a higher propensity to perform manual activities and with higher dexterity, possibly coming from a less privileged environment, may find it less costly to complete a vocational curriculum. When both benefits and costs are taken into account, vocational education can be for many the education choice that provides the highest net expected benefit. The availability of this track is also an opportunity that keeps some individuals in school, and reduces the risk of early school leaving.

There is scope for public intervention when the assignment of individuals to different ability levels is determined at least in part by parental background, especially when this background operates as a constraint that precludes choices. Carneiro and Heckman (2002) propose the distinction between short-term and long-term constraints to educational choice, with the former due to lack of economic resources and the latter induced by disadvantaged parental education. When the choice between vocational and academic education is affected by the presence of long-term constraints, public intervention may be desirable early on in an individual life, so as to compensate differences in the environment that affect the development of cognitive and non-cognitive abilities.

There may also be externalities at work. Our own evidence in Sect. 4 suggests that individuals with a more academic education are more likely to engage in voluntary activities and to trust others. These activities spill-over positively on others and on society at large, but the associated benefits are often ignored by singles when deciding which type of educational curriculum to pursue. The presence of these positive externalities suggests that the degree of investment in academic education could be "too low".

Although the presence of long term liquidity constraints and of positive externalities associated to academic education may suggest that the degree of investment in this type of education is lower than the social optimum, we do not recommend that vocational education should be drastically reduced or even eliminated from upper secondary curricula. This is because individuals may differ in their portfolio of skills (practical vs academic) even after the differences in long term constraints have been taken care of. If this is the case, the availability of the vocational option may reduce early school leaving by keeping more practically oriented individuals in school. ${ }^{15}$

Rather the cutting back on vocational studies, perhaps a more promising policy avenue is that of making vocational education as effective as possible, by increasing

15 The fact that in some countries vocational education accounts for the large majority of students in upper secondary education is prima facie evidence that this type of curriculum is not clearly dominated by more academic education. 
its expected benefits. Will the recent evolution of education policy promoted by the EU, which includes the emphasis on facilitating transitions between vocational and academic tracks, a higher flexibility in the design of curricula and the promotion of a better integration between vocational education at school and training at work, help in this direction? In our empirical research we have asked whether the labour market outcomes associated to vocational education are more favourable in the countries where the combination of school and work programs is more advanced. However, we have found no systematic evidence that this is the case.

While we think that the empirical evidence based on PIAAC is interesting, there are drawbacks that should be mentioned: because of the nature of the data and of the comparative perspective, our empirical strategy relies on selection-on-observables. This strategy is based on assumptions that cannot be tested, and that can be rightly questioned. Perhaps a more promising empirical strategy would be that of exploiting natural experiments. When this is done, results are less negative for vocational education than the ones we find. Notice however that the results using natural experiments do not necessarily contradict what we have found in this report, as they refer to particular sub-samples of the population (LATE effects) rather than to average treatment effects applicable to the entire population, as our results do. Needless to say, further research is required to provide firmer conclusions.

While the evaluation of the relative benefits of vocational and academic education that can inform the policy maker and the public is certainly valuable, further research is also needed to assess what policy interventions are more effective at improving the market value of vocational education. A great help to evaluation would be that when new policies are implemented they are also accompanied by pilot experiments designed to provide data for subsequent evaluations.

Open Access This article is distributed under the terms of the Creative Commons Attribution 4.0 International License (http://creativecommons.org/licenses/by/4.0/), which permits unrestricted use, distribution, and reproduction in any medium, provided you give appropriate credit to the original author(s) and the source, provide a link to the Creative Commons license, and indicate if changes were made.

\section{Appendix}

\section{A non-technical introduction to IPWRA}

In this "Appendix" we introduce some preliminary concepts. Education is considered as a multivalued treatment T, i.e. a treatment which can take several alternative modalities $t$. Specifically, let $t=0$ denote education at or below ISCED $2 ; t=1$ vocational education at ISCED $3-4 ; t=2$ academic education at ISCED $3-4 ; t=3$ vocational education at ISCED 5; and $t=4$ academic education at ISCED 5. Any individual $i$ could be assigned ex-ante to any available modality $t=0, \ldots, 4$. Let the potential outcome of individual $i$ under treatment $t$ (i.e. the outcome that $i$ would achieve ex-post if he was really administered treatment $t$ ) be denoted $Y_{i}(t)$. There are five potential outcomes associated with each individual in our setup.

Assessing the influence of IVET on whatever outcome requires the definition of a benchmark. Given that IVET can either be "short" (ending at ISCED 3-4) or "long" 
(ending at ISCED 5) the definition of the appropriate benchmark is not uncontroversial. For the most part of this report, we use two benchmarks, academic education at ISCED 3-4 or 5, depending on the level of education we consider. In this case, treatment $t=0$ is excluded from the analysis. We also contrast vocational education at ISCED 3-4 with education at ISCED 2 or lower $(t=0)$, using the latter as benchmark. In this case both the type and the level of education change between each treatment and the benchmark. We adopt this perspective in Sect. 6.

The (differential) effect of treatment $t$, with respect to the benchmark $t^{\prime}$ for individual $i$ is given by $Y_{i}(t)-Y_{i}\left(t^{\prime}\right)$. In the population, the average treatment effect (ATE) associated to the pair $\left(t, t^{\prime}\right)$

$$
\operatorname{ATE}\left(t, t^{\prime}\right)=E\left[Y_{i}(t)-Y_{i}\left(t^{\prime}\right)\right]=E\left[Y_{i}(t)\right]-E\left[Y_{i}\left(t^{\prime}\right)\right]
$$

The problem here (known as the fundamental problem of statistical inference) is that we observe the potential outcome corresponding to the particular treatment administered to individual $i$ but we don't know what outcome individual $i$ would have achieved if he was administered any alternative treatment. Therefore, the effect of $t$ accruing to a certain individual cannot be determined because the potential outcomes corresponding to the alternative treatments are missing.

The inverse-probability-weighting (IPW) plus regression-adjustment (RA) method, IPWRA hereafter ${ }^{16}$ (Wooldridge 2007, 2010; Cattaneo 2010), resolves this problem of missing data by imputing to each individual the missing potential outcomes. This is done by exploiting information on similar individuals that received alternative treatments. The IPWRA method overcomes the fundamental problem of statistical inference by generating "educated guesses" for all possible potential outcomes open to each individual. Consequently, all ATEs can be readily computed. A particularly attractive property of the IPWRA method is that it is naturally defined in the framework of multivalued treatments.

The imputation procedure implicit in the IPWRA method is valid only under the assumption that assignment to treatment is independent on potential outcomes, conditional on a set of predetermined characteristics $X$ (the so called Conditional Independence Assumption CIA). When CIA holds, and conditional on $X$, assignment to treatment can be considered as good as random, implying that for each cell determined by $X$, each treatment group will have the same composition in terms of potential outcomes and individual characteristics.

In this paper, the identification assumption is that assignment to treatment is as good as random conditional to a person age, a set of family background indicators (parents education, books at home, immigration status) and country specific conditions at the age when individuals were supposed to choose her schooling track (pupil/teacher ratio in primary school and proportion of residents in rural areas at the age of selection). The inclusion of family background is motivated by the fact that preferences, abilities and attitudes are largely influenced by the parents. Parental and children education levels are highly correlated. To illustrate, in our final sample $65 \%$ of the individuals aged between 25 and 64 whose father achieved a college degree also attained ISCED 5

16 The IPWRA estimator is also known as Wooldridge's double-robust estimator. 
education, compared to only 30 and $38 \%$ of individuals whose father attained ISCED 2 and $3 \mathrm{C}$. The number of books at home at early age, that captures parental education, income and attitude towards education, has been shown to have far reaching consequences on returns to education and consequently on school choice (see Brunello et al. 2017). Parental education is also a good proxy of parental income and of the presence of short run and long run constraints, as defined by Carneiro and Heckman (2002).

We are aware that our identification assumption is rather strong. For instance, it is well known that students with motivation and behavioural problems tend to select into vocational tracks. In part, these problems are the result of the early environment these students grew up in, that we capture with parental education and books in the house. Our controls, however, fail to capture those components of motivation and behaviour that do not depend on parental background. If these components are correlated both with outcomes and with the selected school curriculum, our estimates may still reflect to some extent selection effects, and should therefore interpreted with due caution.

Under CIA the average treatment effects $\operatorname{ATE}\left(t, t^{\prime}\right)$ can be identified. Conditional independence implies that, for all possible $t, E\left[Y_{i}(t) \mid X\right]=E\left[Y_{i}(t) \mid t_{i}(t)=1, X\right]$, where the condition $t_{i}(t)=1$ defines the set of individuals assigned to treatment $t$. Conditional on $X$, the average outcome in the population coincides with the average outcome in the sub-population receiving treatment $t$. It follows that

$A T E\left(t, t^{\prime} \mid X\right)=E\left[Y_{i}(t)-Y_{i}\left(t^{\prime}\right) \mid X\right]=E\left[Y_{i}(t) \mid t_{i}(t)=1, X\right]-E\left[Y_{i}\left(t^{\prime}\right) \mid t_{i}\left(t^{\prime}\right)=1, X\right]$

i.e. the ATE of treatment $t$ with respect to $t^{\prime}$, conditional to $X$, can be computed by comparing the average outcome of the individuals treated with $t$ and the average outcome of the individuals treated with $t^{\prime}$. Averaging over $\mathrm{X}$, we have

$$
\operatorname{ATE}\left(t, t^{\prime}\right)=E_{X}\left[\operatorname{ATE}\left(t, t^{\prime} \mid X\right)\right]
$$

Note that for ATE to be correctly defined, the cell characterized by $X=x$, for all possible $\mathrm{x}$, must include both subjects assigned to treatment $t$ and subjects assigned to treatment $t^{\prime}$. Otherwise $\operatorname{ATE}\left(t, t^{\prime} \mid X=x\right)$ cannot be evaluated. This condition is called common support or overlapping. In our empirical estimates, we always verify that overlap holds.

We conclude this "Appendix" with two final remarks. First, compared to simple RA (regression adjustment) estimators, which require defining only the outcome model, the combination of IPW and RA has the advantage of being doubled robust to misspecification. Indeed, the IPWRA estimator is an RA estimator that uses estimated inverse-probability weights obtained from the treatment model to correct the estimator when the outcome model is mis-specified. If the outcome model is correctly specified, the weights do not affect the consistency of the estimator (Wooldridge 2007).

Second, the differential effect of vocational education depends on the quantity, quality and market value of the skills and competences that vocational and academic education contribute to accumulate (the direct effect) but also on occupational alternatives and, more in general, on the opportunities that the two types of schooling open up to the students later in their lives (the indirect effect). Typically, those with higher 
academic education are more likely to end up in high-skill jobs, compared to other education careers, and thereby have access to higher wages, longer working hours, and a stronger pressure to update and expand skills and competences. With PIAAC data and the setting presented in this Section, we cannot distinguish between the direct and the indirect effect and only estimate the total effect.

\section{IPWRA implementation}

The IPWRA method is composed of three steps:

(1) From a multinomial logit model (the treatment model),

$$
p(T=t)=\Lambda\left(X \gamma_{t}\right) \quad \text { for all } t=0, \ldots, 4
$$

the inverse predicted probabilities of treatment $d_{i}(t)=\frac{1}{p_{i}(t)}$ for $t=0, \ldots, 4$ are derived for all possible treatments;

(2) Separately for each treatment $t$, the corresponding potential outcome is predicted for all individuals (both the individuals assigned to treatment $t$ and those assigned to other treatments $t^{\prime} \neq t$ ). Predictions rely on the parameters of the following linear model (the outcome model):

$$
Y_{i}(t)=X \beta+\varepsilon \quad \text { for all } t=0, \ldots, 4
$$

which is estimated by weighted least squares, with weights given by the normalized inverse probability of treatment $\bar{d}_{i}(t)=\frac{d_{i}(t)}{\sum_{i \mid t_{i}(t)=1} d_{i}(t)} \div \frac{1}{N_{t}}$. Observations less likely to receive treatment $t$, according to the treatment model, but which are nonetheless administered treatment $t$ are weighted more. The intuition behind this procedure is simple. Suppose that individuals with given characteristics $X=x$ tend to self-sort in treatment $t$.

Then in treatment $t$ characteristics $X=x$ would be over-represented and characteristics $X=x^{\prime}$ with $x^{\prime} \neq x$ under-represented. This fact is acknowledged by the treatment model, which assigns a higher probability of been administered treatment $t$ to individuals with $X=x$ and lower probability to those with $X=x^{\prime}$. Thus, by weighting both groups with their inverse probability of treatment in the outcome model, the composition of the sample which has received treatment $t$ is re-balanced.

(3) ATEs are obtained by comparing the sample means (taken over the entire sample) of the predicted potential outcomes. Efficiency is achieved when weights, predictions and ATEs are simultaneously estimated by a GMM estimator (Cattaneo 2010).

Alternatively, consistent point estimates with somewhat larger standard errors can be obtained by bootstrapping the three-steps procedure described above. In this report, we take this route because it readily offers the possibility of estimating ATEs for particular subgroups, such as the young and the old. Denote $\Delta_{i}\left(t, t^{\prime}\right)$ 
the difference in the potential outcomes predicted to individual $i$ from step 2. We replace step 3 by estimating the following regression

$$
\Delta_{i}\left(t, t^{\prime}\right)=a_{0}+a_{1} O L D+\varepsilon
$$

(where OLD is dummy that takes the value 1 for senior individuals and 0 otherwise), that yields $a_{0}=\operatorname{ATE}\left(t, t^{\prime} \mid O L D=0\right)$ and $a_{1}=\operatorname{ATE}\left(t, t^{\prime} \mid O L D=\right.$ 1) $-A T E\left(t, t^{\prime} \mid O L D=0\right)$, i.e. the ATEs for the young and the differential ATE for the old. To compute any ATE of interest we bootstrap the entire procedure 250 times. Compared to the efficient simultaneous procedure, bootstrapped standard errors are only marginally larger.

We run the IPWRA procedure separately by country and gender for any outcome we consider. This strategy yields less precise estimates, because of the smaller sample size, but a better fit and more reliable estimates of the probability of treatment.

\section{References}

Altonji J, Blom E, Meghir C (2012) Heterogeneity in human capital investments: high school curriculum, college major, and careers. Annu Rev Econ 4:185-223

Angrist J, Pischke S (2008) Almost harmless econometrics. MIT Press, Cambridge

Baethge M, Arends L (2009) Feasibility study VET-LSA, SOFI. Mimeo, New York City

Bibby D, Buscha F, Cerqua A, Thomson D, Unwin P (2014) Estimation of the labour market returns to qualifications gained in English further education. Department for Business Innovation \& Skills, UK Government, London

Bishop JH, Mane F (2004) The impacts of career-technical education on high school labour market success. Econ Educ Rev 23(4):381-402

Brunello G, Weber G, Weiss C (2017) Books are forever: early life conditions, education and lifetime earnings in Europe. Econ J 127(600):271-96

Brunello G, Rocco L (2015) The effects of vocational education on adult skills and wages: what can we learn from PIAAC? OECD Social, Employment and Migration Working Papers 168, OECD Publishing

Cameron AC, Miller DL (2013) A practitioner's guide to cluster-robust inference. J Hum Resour 50(2):317372

Carneiro P, Heckman J (2002) The evidence on credit constraints in post-secondary schooling. Econ J R Econ Soc 112(482):705-734

Cattaneo MD (2010) Efficient semiparametric estimation of multi-valued treatment effects under ignorability. J Econ 155(2):138-154

CEDEFOP (2012) Trends in VET policy in Europe 2010-2012. Progress towards the Bruges communiqué. Publications Office of the European Union, Luxembourg

Checchi D, Flabbi L (2007) Intergenerational mobility and schooling decisions in Germany and Italy: the impact of secondary school tracks. IZA Discussion Paper, No. 2876, Institute for the Study of Labor (IZA) and Italy: the impact of secondary school tracks. IZA Discussion Paper, No. 2876, Institute for the Study of Labor (IZA)

Dearden L, McIntosh S, Myck M et al (2002) The returns to academic and vocational qualifications in Britain. Bull Econ Res 54(3):249-274

Dearden L, McGranahan L, Sianesi B (2004) An in-depth analysis of the returns to national vocational qualifications obtained at level 2, Centre for the Economics of Education, CEE Discussion Papers, No. 0046

Fersterer J et al (2008) Returns to apprenticeship training in Austria: evidence from failed firms. Scand J Econ 110(4):733-753 
Hall C (2012) The effects of reducing tracking in upper secondary school: evidence from a large-scale pilot scheme. J Hum Resour 47(1):237-69

Hotchkiss L (1993) Effects of training, occupation, and training-occupation match on wage. J Hum Resour 28(3):482-496

Lavrijsen J, Nicaise I (2014) Life cycle patterns in the labour market returns to vocational education. Leuven University, Leuven

Malamud O, Pop-Eleches C (2010) Academic education versus vocational training: evidence from an economy in transition. Rev Econ Stat 92(1):43-60

Meer J (2007) Evidence on the returns to secondary vocational education. Econ Educ Rev 26(5):559-73

OECD (2013) The survey of adult skills. A Reader's Companion, Paris. doi:10.1787/9789264204027-en

Oosterbeek H, Webbink D (2007) Wage effects of an extra year of basic vocational education. Econ Educ Rev 26(4):408-19

Pischke JS, von Wachter T (2008) Zero returns to compulsory schooling in Germany: evidence and interpretation. Rev Econ Stat 90(3):592-98

Quintini Glenda, Manfredi Thomas. Going separate ways? school-to-work transitions in the United States and Europe, Social, Employment and Migration Working, No. 90, OECD, Paris, doi:10.1787/ 221717700447

Ryan P (2001) The school-to-work transition: a cross-national perspective. J Econ Lit 39(1):34-92

Statistics Norway (2013) Forecasting demand and supply of labour by education. Statistics Norway, Oslo

Wooldridge JM (2007) Inverse probability weighted estimation for academic missing data problems. J Econ 14:1281-1301

Wooldridge JM (2010) Econometric analysis of cross section and panel data, 2nd edn. MIT Press, Cambridge

\section{Publisher's Note}

Springer Nature remains neutral with regard to jurisdictional claims in published maps and institutional affiliations. 